Sādhanā Vol. 40, Part 2, April 2015, pp. 577-590. (C) Indian Academy of Sciences

\title{
Performance assessment of indigenously developed FBG strain sensors under short-term and long-term loadings
}

\author{
$\mathrm{K}_{\text {KESAVAN }}^{1, *}$, B ARUN SUNDARAM ${ }^{1}$, \\ A K FARVAZE AHMED ${ }^{1}$, S PARIVALLAL ${ }^{1}$, P BISWAS $^{2}$, \\ $\mathrm{S}_{\text {BANDYOPADHYAY }}{ }^{2}$, K RAVISANKAR ${ }^{1}$ and UMESH TIWARI ${ }^{3}$ \\ ${ }^{1}$ CSIR-Structural Engineering Research Centre, Council of Scientific and Industrial \\ Research, Chennai 600 113, India \\ ${ }^{2}$ Central Glass and Ceramic Research Institute, Council of Scientific and Industrial \\ Research, Kolkata 700 032, India \\ ${ }^{3}$ Central Scientific Instruments Organization, Council of Scientific and Industrial \\ Research, Chandigarh 160 030, India \\ e-mail: kesavankannan@yahoo.com
}

MS received 31 January 2012; revised 5 August 2014; accepted 6 November 2014

\begin{abstract}
Fibre Bragg Grating (FBG) sensors are the most recent type of fibre optic sensors, which are gaining importance in the field of structural health monitoring of civil infrastructure. These are proven to be more versatile due to their distinct advantages such as high sensitivity, immunity to electromagnetic interference, ease of multiplexing and remote sensing. These are suitable for the short-term and longterm monitoring of the structures. Multiple Fibre Bragg Grating (FBG) sensors can be surface mounted and/or embedded in structures to measure strain, temperature, cracks and vibrations. Use of FBG sensors for real time health monitoring of various civil engineering structures is well-established in western world since last decade, whereas in the Indian context this technology is still in a nascent stage. In this paper, performance assessment of indigenously developed FBG sensors for the application of health monitoring of civil engineering structures by conducting short-term and long-term studies is presented. Brief details of the laboratory studies carried out on indigenously developed FBG sensors are covered in this paper. From the laboratory studies it is found that, these FBG sensors are suitable in health monitoring of civil engineering structures.
\end{abstract}

Keywords. Indigenously developed FBG strain sensor; tension test; compression test; concrete cylinder; thermal strain; temperature; long-term and short-term loading; strain measurement/monitoring.

*For correspondence 


\section{Introduction}

Civil engineering structures such as buildings, bridges, dams, tunnels, ports, etc., are most important and expensive assets of modern society that need to be functional for a very long time under complex conditions, thus their constant monitoring is pivotal to prevent catastrophe and ensure safety. Health monitoring of civil structures involves stricting the periodic maintenance procedures, regular visual inspections and use of conventional sensors i.e., electrical resistance strain gage. Periodic maintenance of structures is expensive and visual inspection mostly miss critical problems. Conventional instrumentation techniques for monitoring the performance of existing and new structures are mainly limited to the application of electric and magnetic principles used in electrical resistance strain gages, linear differential transducers, etc. While these can serve well for short-term measurements, they have major limitations in evaluating long-term behaviour of structural members, especially in concrete structural systems. The main problems associated with these conventional instrumentation techniques stem from their response to ambient electrical noise and potential for degradation with age and not suitable for multiplexing and long distance applications.

Over the last few years, optical fibre sensors have seen an increased acceptance as well as a wide spread use for structural sensing and monitoring applications in civil engineering, aerospace, marine, oil and gas, composites and smart structures. Recent developments in fibre optic sensor systems have the potential to offer advantages that can essentially eliminate conventional sensor deficiencies and permit long-term reliable quantitative monitoring. The advantages of fibre optic sensors over conventional sensors are small physical size, less weight, flexibility, immunity to Electro Magnetic Interferences (EMI), resistance to corrosion, high resolution, large band width of signal, practically no noise and high sensitivity. If protected from breakage they can operate without degradation for decades. Fibre-sensing technology, though comparatively new, constitutes $75 \%$ of the fibre optical sensors used in structural health monitoring (Udd 1995; Culshaw and Dakin 1996; Kathy 2006). Cabling problem can be reduced significantly with the use of optical fibre and they are having ability to be embedded in the structure under common construction environment. Multiple FBGs can be surface mounted and/or embedded in structures to measure strain, temperature (Singh et al 2007), cracks and vibrations. Other parameters can also be measured by designing appropriate coatings or transducers. Use of FBG sensors for real time health monitoring of various civil structures is well-established in western world since last decade (Schulz et al 1998; Rao 1999; Tenntson et al 2001; Majumder et al 2008; Kersey et al 1997), whereas in India, this technology is still in a nascent stage. This technique can specify timely warning which can prevent damage and do corrective action when defect is small/less and thus large expenditure on unnecessary repair is saved. Practical implementation of these sensors requires their indigenous development as importing the FBGs is an expensive and time consuming process. In this paper, the short-term and long-term performance of the indigenously developed FBG sensor under different loads is presented.

\section{Fibre optic sensor}

Fibre optic sensors can be classified under different categories. Localised, distributed and multiplexed sensors are based on sensing methods (Udd 1995). Intensity, interferometric, polarimetric and spectrometric based sensors are classified according to the transduction mechanism. Fibre optic sensors are often categorized as being either extrinsic or intrinsic. Extrinsic or hybrid fibre

optic sensors have an optic fibre carries a light beam to and from a 'light modulator', which in 
response to an environment effect modulates the light beam. Intrinsic fibre optic sensors measure the modulation of light due to an environmental effect, within the fibre.

\subsection{Fibre bragg grating}

Fibre Bragg Grating (FBG) sensors are the most promising optical fibre sensors based on the state-of-the-art technologies. FBGs have initially begun to be used extensively in the telecommunication industry for dense wavelength division, de-multiplexing, laser stabilization and erbium amplifier gain flattening at $1550 \mathrm{~nm}$ wavelength range. In addition, the characteristics that an FBG reflects a specific wavelength that shifts slightly depending on the strain applied are ideal for mechanical sensing.

\subsection{Principle of fibre bragg grating sensors}

Hill et al (1978) first observed fibre photosensitivity in germanium-doped silica fibre. Since then entire class of in-fibre components, called the Fibre Bragg Grating (FBG), have been introduced. Fibre Bragg Gratings are periodic structures that are imprinted directly into the core of glass optical fibre by powerful ultraviolet radiation. Such structure consists of a periodically varying refractive index over typically several millimeters of the fibre core. The specific characteristic of FBG for sensing applications is that their periodicity causes them to act as wavelength sensitive reflectors.

During imprinting process, the intensity of the ultraviolet illumination is made to occur in a periodic fashion along the fibre core. At a sufficiently high power level, local defects are created within the core, which then give rise to a periodic change in the local refractive index. Figure 1 shows the refractive index profile on FBG. This change in refractive index (RI) created are permanent and sensitive to a number of physical parameters, such as pressure, temperature, strain and vibration. Thus by monitoring the resultant changes in reflected wavelength, FBG can be used for sensing applications to measure various physical quantities.

In a single mode optical fibre, light is guided along the axis of the core in the fundamental mode. When light passes through an FBG, Fresnel reflection takes place due to the variation in
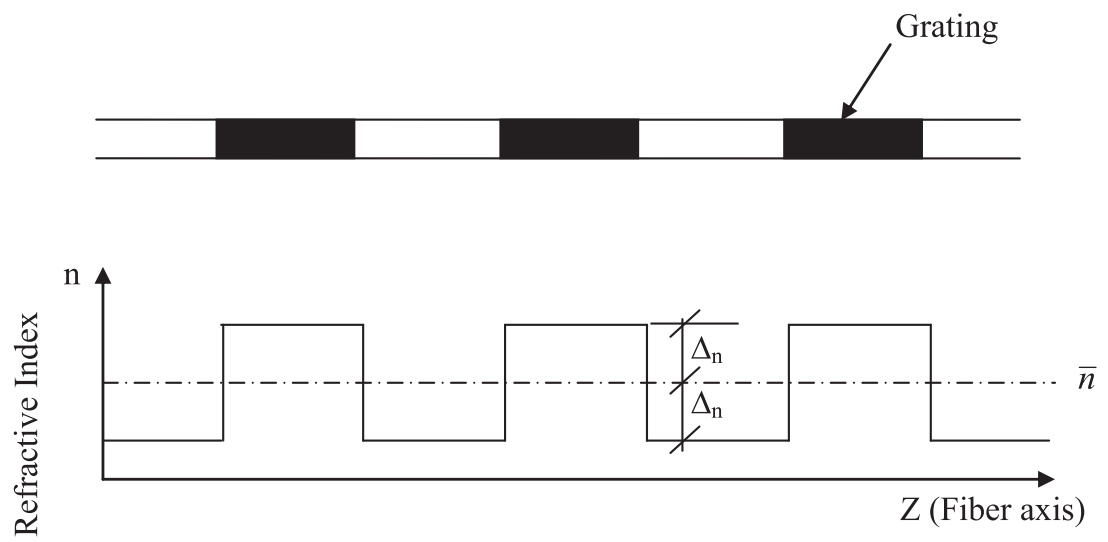

Where, $\Delta_{\mathrm{n}}=$ depth of refractive index modulation

Figure 1. Typical refractive index profile on FBG. 

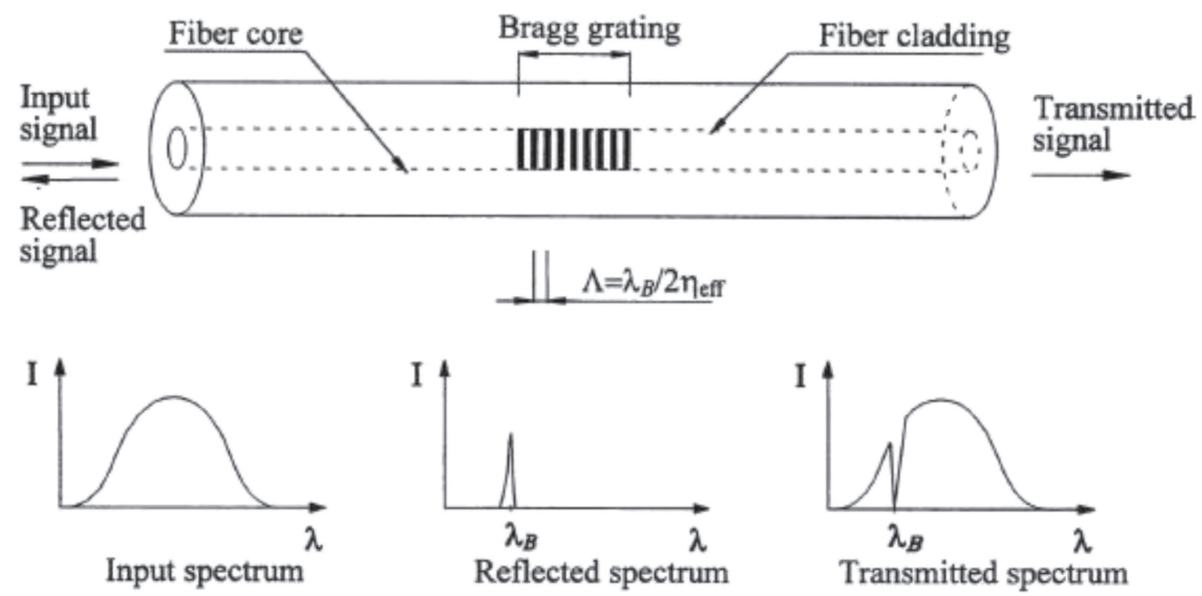

Figure 2. Principle of operation of a fibre Bragg grating sensor.

refractive index. Fibre Bragg Grating sensor response arises from two sources (figure 2), namely the induced change in pitch length $(\Lambda)$ of the grating and refractive index $\eta_{\text {eff. }}$. The wavelength of the reflected spectrum band is defined by the Bragg condition.

$$
\lambda_{B}=2 n_{e f f} \Lambda,
$$

where, $n_{\text {eff }}=$ effective core refractive index, $\Lambda=$ induced change in pitch length/ grating period, $\lambda_{B}=$ Bragg wavelength.

When an FBG is strained, the Bragg wavelength $\left(\lambda_{B}\right)$ changes due to change in grating spacing $(\Lambda)$ and the change in refractive index $\left(n_{e f f}\right)$. Thus the Bragg wavelength changes due to applied strain. The theoretical relationship between change in wavelength and strain has been established as perturbation of the effective core refractive index $\left(n_{\text {eff }}\right)$.

$$
\frac{\Delta \lambda_{B}}{\lambda_{B}}=\left(1-p_{e}\right) \varepsilon,
$$

where, $\Delta \lambda_{B}=$ change in Bragg wavelength $\left(\lambda-\lambda_{B}\right), \lambda_{B}=$ initial Bragg wave length, $\lambda=$ Bragg length after straining/loading, $p_{e}=$ effective photo elastic constant for the fibre $(\sim 0.22)$, $\varepsilon=$ strain.

From Eq. (2)

$$
\varepsilon=\frac{\Delta \lambda_{B} / \lambda_{B}}{\left(1-p_{e}\right)}
$$

\section{Experimental studies}

\subsection{Short-term studies}

Laboratory experiments were carried out to study the performance of indigenously developed FBG sensors under short-term loadings like tension, compression and temperature. These FBG sensors are surface mountable type. These FBG sensors are developed by Central Glass and Ceramic Research Institute, Kolkata and Central Scientific Instruments Organization (CSIO), 
Chandigarh. The FBG sensors are apodized gratings with physical length of about $5 \mathrm{~mm}$ were inscribed on hydrogen loaded fibre using a $248 \mathrm{~nm}$ UV laser exposure with a phase mask. The reflectivity of grating was $\sim 50 \pm 5 \%$ with $>35 \mathrm{~dB}$ peak to side-lobe suppression. Grating zones were recoated with polyimide and were annealed at $1500^{\circ} \mathrm{C}$ for $12 \mathrm{~h}$.

Tests were conducted on steel and concrete specimens. The strain responses from indigenous FBG sensors were compared with electrical resistance strain gages and imported fibre optic sensors.

3.1a Tension test: In order to assess the behaviour of indigenous FBG sensors, experiments were conducted on standard tension specimens. For this study, two mild steel tension specimens were prepared as per ASTM E 8M-04 for conducting tension test. Specimen-1 was instrumented with an indigenous FBG sensor (FBG-Ind) and an electrical resistance strain gage of $5 \mathrm{~mm}$ long (SG1) on one side and other side was instrumented with a weldable type imported FBG sensor (FBG-Imp) and an electrical resistance strain gage (SG2) as shown in figure 3. FBG-Ind is a single FBG of $15 \mathrm{~mm}$ length having Bragg wavelength of $1545.618 \mathrm{~nm}$. FBG-Imp is a weldable type FBG sensor having Bragg wave length of $1555.2 \mathrm{~nm}$.

FBG sensor (FBG-Ind) and electrical resistance strain gages were bonded on the specimen using suitable strain gage adhesive after proper surface preparation. FBG sensor (FBG-Imp) was installed on the specimen by means of spot welding. The instrumented specimen was tested under tension load in Universal Testing Machine (UTM). The load was applied in steps of $4 \mathrm{kN}$ up to $20 \mathrm{kN}$ (figure 4). Commercially available FBG Interrogator was used to measure the wavelength from FBG sensors. Strain values from electrical resistance strain gages were recorded by means of microprocessor based strain gage data logger. Responses like wavelength and strain from FBG sensors and electrical resistance strain gages were recorded during each increment of loading. The wavelength readings were converted into strain by using the Eq. (3). Two cycles of loading and unloading were carried out to check the reliability of the measurements. Load vs strain (figure 5) were plotted to evaluate the comparative performance of FBG sensors. The agreement of values between the FBG sensor and conventional strain gage is fairly good with $3 \%$ variation.

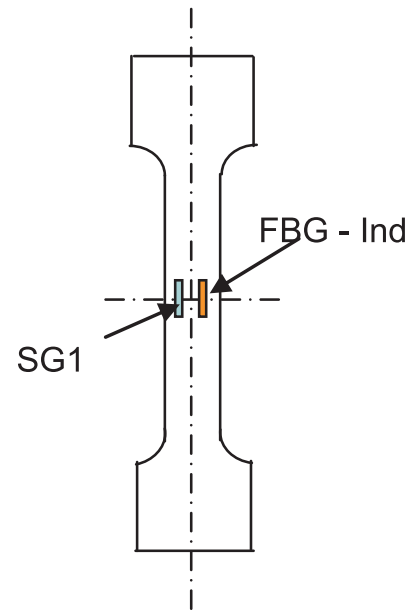

Side 1

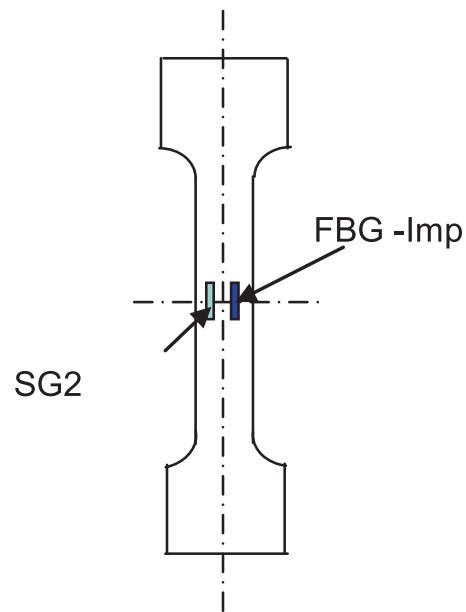

Side 2

Figure 3. Instrumentation details of tension specimen-1. 


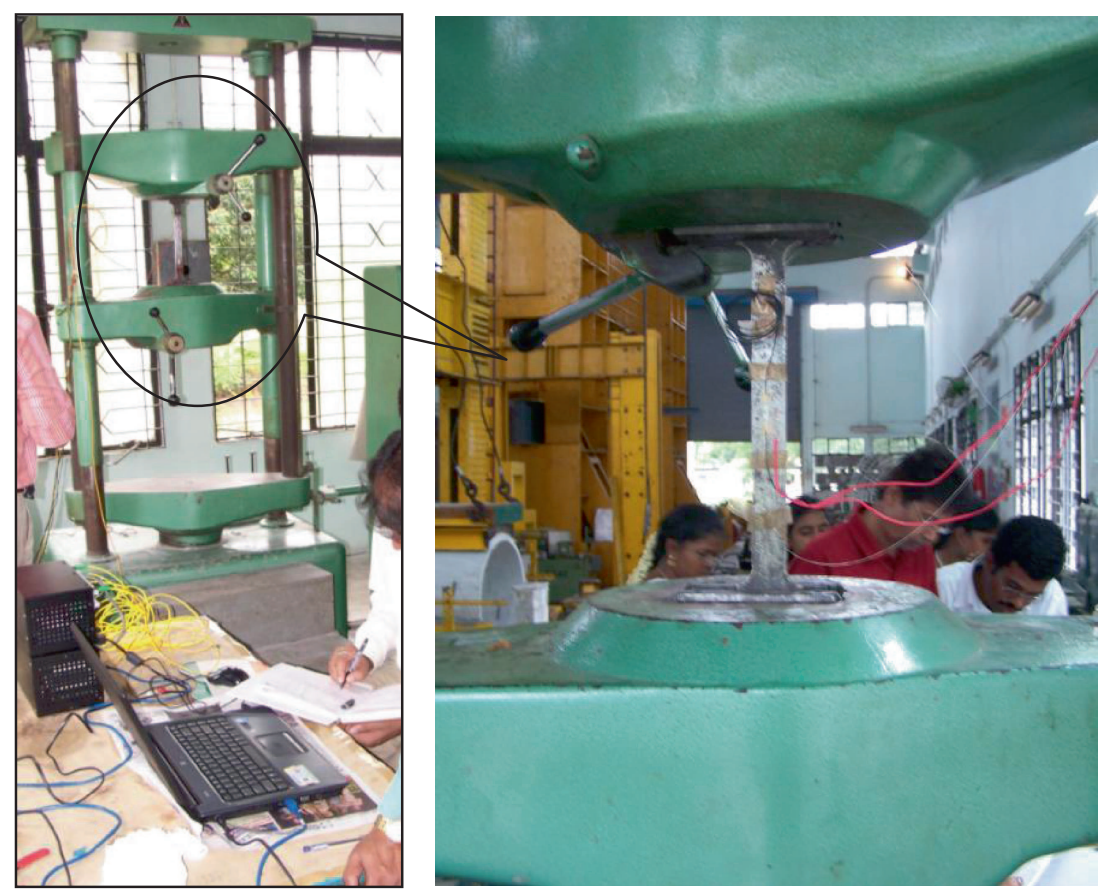

Figure 4. Tension test on mild steel specimen 1.

To evaluate the performance of indigenously developed dual FBG sensor, specimen 2 was instrumented with indigenous dual FBG sensor of $20 \mathrm{~mm}$ grating length each with wave length 1545.544 and $1550.424 \mathrm{~nm}$. Two electrical resistance strain gages (SG1 and SG2) of size $5 \mathrm{~mm}$ were instrumented adjacent to the each grating (FBG1 and FBG2), as shown in figure 6. The instrumented specimen was tested under tension in UTM. The load was applied in steps of 4 up to $20 \mathrm{kN}$. The responses from FBG sensors and electrical resistance strain gages were recorded. To ensure the reliability of the measurement, the test was repeated twice. Figure 7

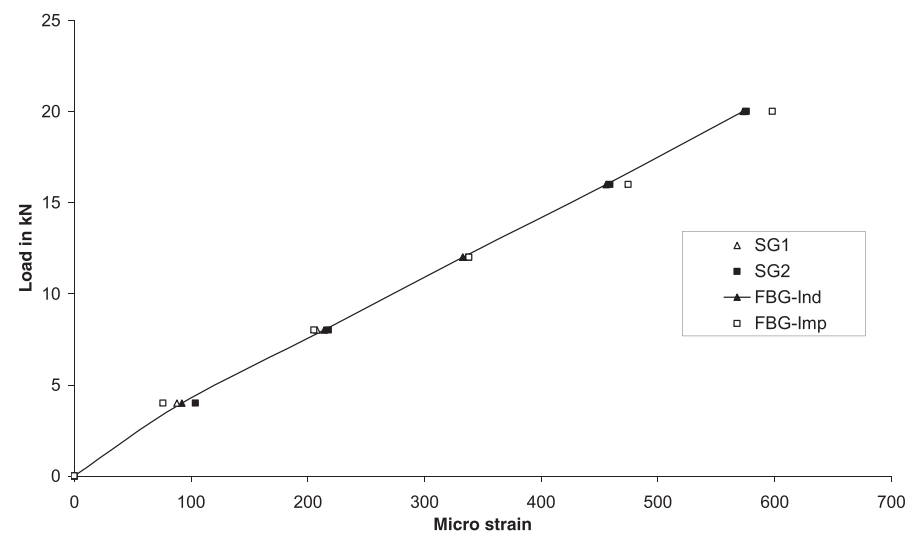

Figure 5. Load vs strain obtained from tension specimen-1. 


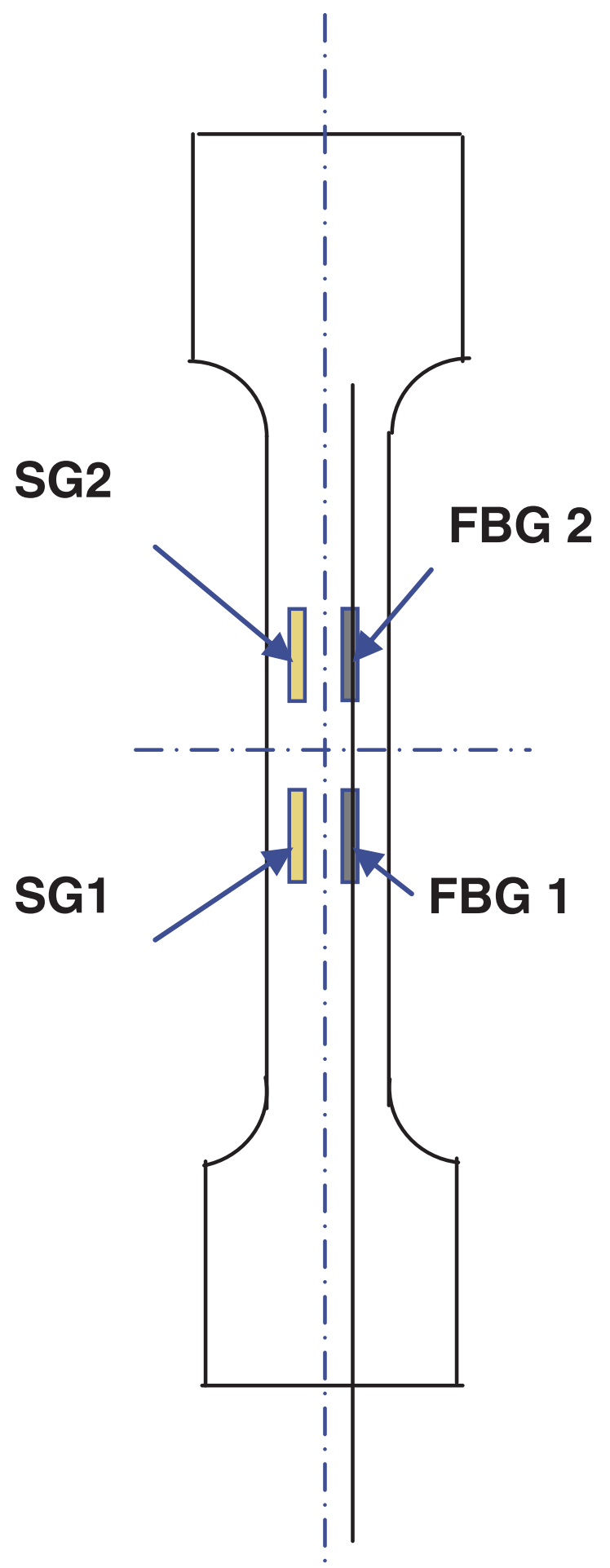

Figure 6. Instrumentation details of mild steel tension specimen-2. 


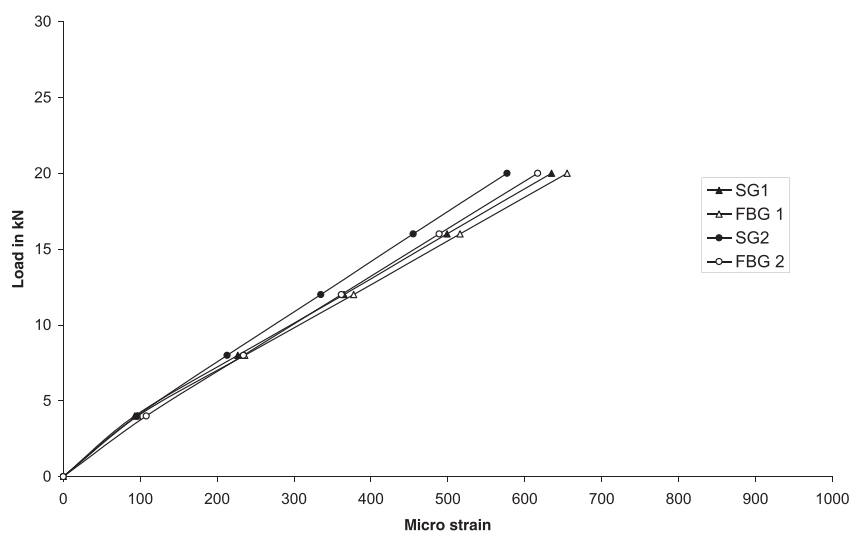

Figure 7. Load vs strain obtained from tension specimen-2.

shows the comparative performance of FBG sensors with electrical resistance strain gages with $3.6 \%$ variation.

3.1b Compression test: To assess the performance of an indigenous FBG sensor under compression, tests were conducted on concrete cylinder of $150 \mathrm{~mm}$ dia and $300 \mathrm{~mm}$ long. In this experiment an FBG sensor with three gratings of $30 \mathrm{~mm}$ (FBG1, FBG2 and FBG3), interspacing of $300 \mathrm{~mm}$, nominal wavelengths of $1545.49,1550.410$ and $1555.348 \mathrm{~nm}$, respectively were bonded on the surface of the concrete cylinder as shown in figure 8. Electrical resistance strain gage of size $30 \mathrm{~mm}$ (SG1, SG2 and SG3) was bonded near each FBG grating to compare the responses from FBG sensor.

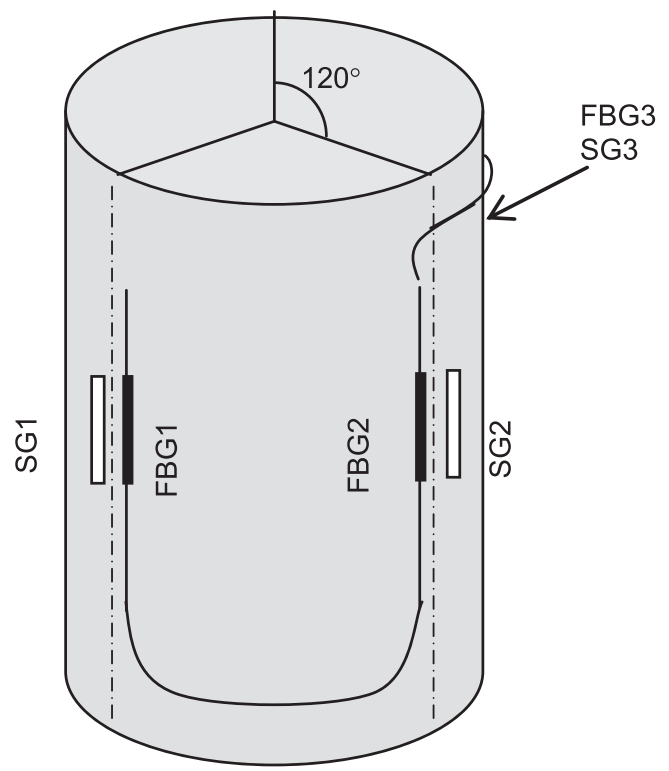

Figure 8. Instrumentation details of concrete cylinder for compression test. 
The instrumented concrete cylinder was tested under compression in UTM. The load was applied in steps of $50 \mathrm{kN}$ up to $300 \mathrm{kN}$. The responses from FBG sensors and electrical resistance strain gages were recorded. The average value of strain measured from three FBG sensors and electrical resistance strain gages were compared. To ascertain the reliability of measurement, the test was conducted twice. Figure 9 shows the typical load vs average strain measured from FBG sensor and electrical resistance stain gage for concrete cylinder under compression with $4 \%$ variation.

3.1c Temperature study: To study the performance of indigenous FBG senor for the measurement of thermal strain and temperature, an experiment was conducted on a steel specimen. The specimen instrumented with FBG sensors and resistance based temperature sensors.

For this experiment, a dual FBG Sensor each with grating length of $15 \mathrm{~mm}$ and Bragg wavelengths at 1551.495 and $1556.454 \mathrm{~nm}$ was used. One FBG sensor with a central wavelength of $1551.495 \mathrm{~nm}$ was bonded with the adhesive on the surface of a mild steel specimen and the second FBG sensor with central wavelength of $1556.454 \mathrm{~nm}$ was kept free ended on the surface of specimen for sensing temperature. Conventional resistance based temperature sensor was also fixed to measure temperature as shown in figure 10.

The specimen mounted with FBG sensors and strain gage based temperature sensor was placed inside a oven and temperature initialization was done at ambient temperature of $26.4^{\circ} \mathrm{C}$ and recorded the initial values of FBG sensor, strain gage bases temperature sensor. Then the temperature was increased up to $65^{\circ} \mathrm{C}$ at $5^{\circ} \mathrm{C}$ interval, corresponding wavelength shifts in both FBG sensors and strain values from temperature sensor (resistance based) were recorded.

The Bragg wavelength shifts in both the FBGs are same due to change in temperature, while additional effect of strain results in larger wavelength shifts for the FBG which is surface mounted. Wavelength shift due to temperature is subtracted from total shift of the first FBG to get the thermal strain alone due to temperature. Figure 11 shows the thermal strain measured from the mild steel specimen. Temperature is obtained from the Bragg wavelength shift

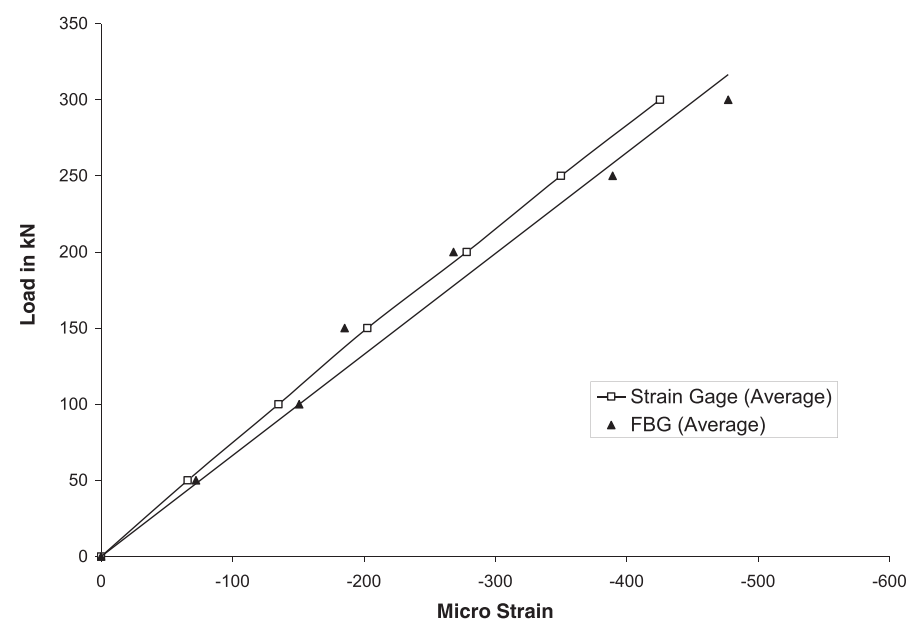

Figure 9. Load vs strain obtained for cylinder from compression test. 


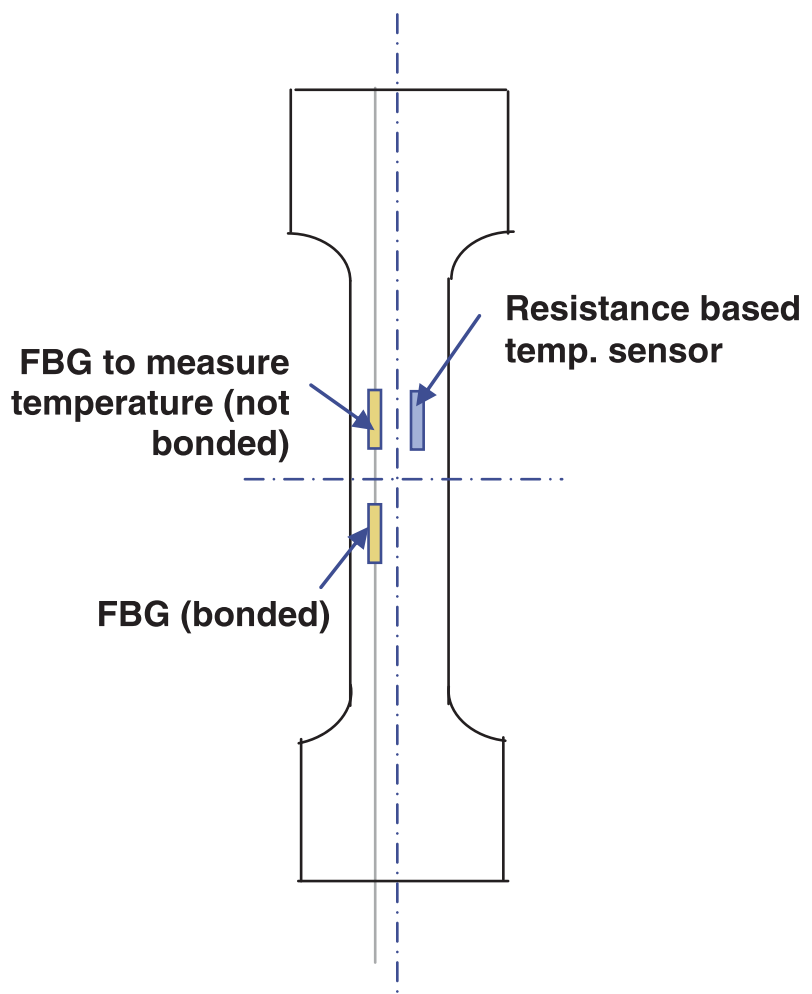

Figure 10. Instrumentation details for temperature measurement.

measured from the FBG sensor which is not bonded. If the Bragg wave length shift includes the effect of temperature, then Eq (2) can be changed as Eq (4).

$$
\frac{\Delta \lambda_{B}}{\lambda_{B}}=\left(1-p_{e}\right)\left(\varepsilon_{m}+\alpha_{s p} \Delta_{T}\right)+\alpha_{s} \Delta_{T},
$$

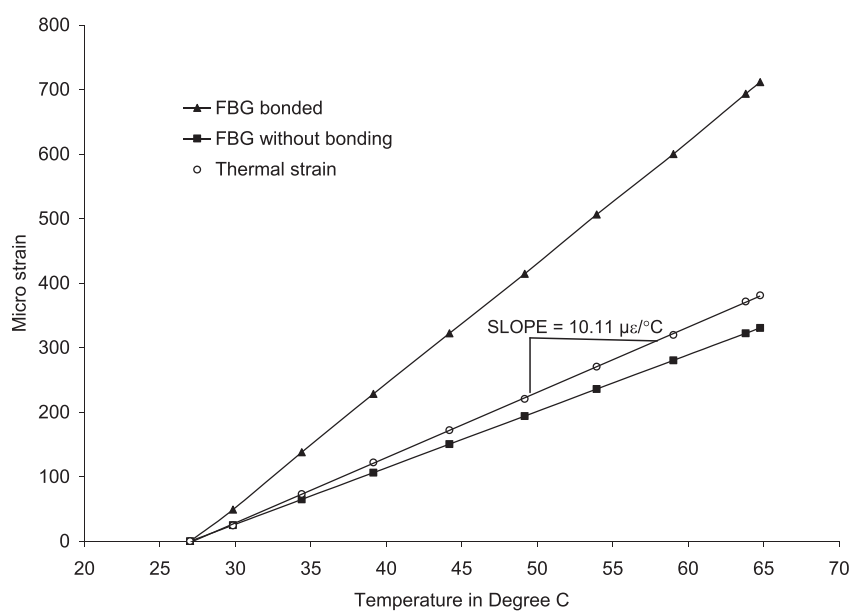

Figure 11. Temperature measurement from FBG sensor on mild steel specimen. 
Table 1. Comparison of temperature measured from FBG sensor and resistance based temperature sensor.

\begin{tabular}{ll}
\hline $\begin{array}{l}\text { Temperature measured from strain } \\
\text { gage based temperature sensor }\left(\text { in }{ }^{\circ} \mathrm{C}\right)\end{array}$ & $\begin{array}{l}\text { Temperature measured } \\
\text { from indigenous FBG }\left(\text { in }{ }^{\circ} \mathrm{C}\right)\end{array}$ \\
\hline 27 & 27 \\
30 & 30 \\
35 & 34 \\
40 & 39 \\
45 & 44 \\
50 & 49 \\
55 & 54 \\
60 & 59 \\
65 & 64 \\
\hline
\end{tabular}

where, $\varepsilon_{m}=$ mechanically induced strain, $\alpha_{s p}=$ thermal expansion co-efficient of specimen, $\alpha_{S}=$ thermo-optic co-efficient of fibre $\left(5-8 \times 10^{-6}\right.$ per $\left.{ }^{\circ} \mathrm{C}\right), \Delta_{T}=$ change in temperature.

If there is no mechanically induced strain, Eq (4) can be modified as Eq (5)

$$
\begin{gathered}
\frac{\Delta \lambda_{B}}{\lambda_{B}}=\alpha_{s} \Delta_{T} \\
\Delta_{T}=\left(\frac{\Delta \lambda_{B}}{\lambda_{B}}\right) / \alpha_{s} .
\end{gathered}
$$

By assuming $\alpha_{s}$ as $7 \times 10^{-6}$ per $^{\circ} \mathrm{C}$, temperature also calculated and compared with temperature measured from strain gage based temperature sensor (table 1).

\subsection{Long-term studies}

Experimental studies were carried out to assess the long-term stability of indigenous FBG sensors subjected to sustained loading. For this study, two $7 \mathrm{~mm}$ diameter high strength pre-stressing wire was instrumented with FBG sensors. One wire was instrumented with one indigenously developed dual FBG (FBG-Ind) sensor (one for strain measurement and other for temperature measurement) and an imported FBG (FBG-Imp) sensor for comparison. Another wire was instrumented with one indigenously developed FBG (FBG-Ind) sensor and one imported FBG (FBG-Imp) sensor for comparison.

Two self straining frames were specially designed and fabricated for this study and the instrumented pre-stressing wires were tensioned by means of a hydraulic jack (figure 12). After locking the pre-stressing force on the instrumented wire suitably, the strains from the FBG sensors were measured. The initial pre-stressing force in specimen one (SP-1) and specimen two (SP-2) was 670 and $850 \mathrm{MPa}$, respectively. Strain values from all the sensors in SP-1 and SP-2 were measured for about 500 days. The measured strain data for duration of 500 days was corrected for temperature effect and strain vs. time (no. of days) was plotted (figure 13). The strain output is almost constant during this period and also compared with imported FBG sensors, indicating that indigenously developed FBG sensors are stable and suitable for long-term monitoring of structures. 


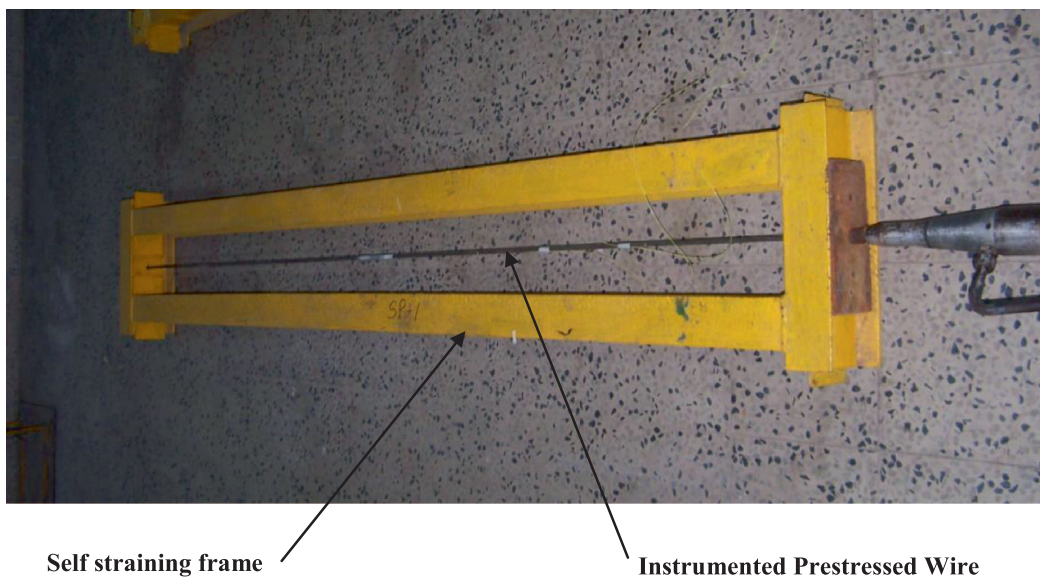

Figure 12. Experimental set-up for long-term stability assessment of FBG sensor.

\subsection{Cyclic load test}

Performance evaluation of indigenously developed FBG sensors under cyclic loading was done on a steel unequal I-specimen subjected to cyclic loading. One indigenously developed surface mounting FBG sensor (FBG-Ind) along with an imported surface mounting FBG sensor(FBGImp) were mounted on the steel specimen using suitable adhesive. The specimen was tested under two point bending with span of $1500 \mathrm{~mm}$ and a constant bending zone of $150 \mathrm{~mm}$ (figure 14). The specimen was tested with the load range from 44 to $220 \mathrm{kN}$ with the frequency of $4 \mathrm{~Hz}$. It was tested up to 2 million cycle of load. The response from the two different sensors was monitored at regular intervals and found to be matching well (figure 15).

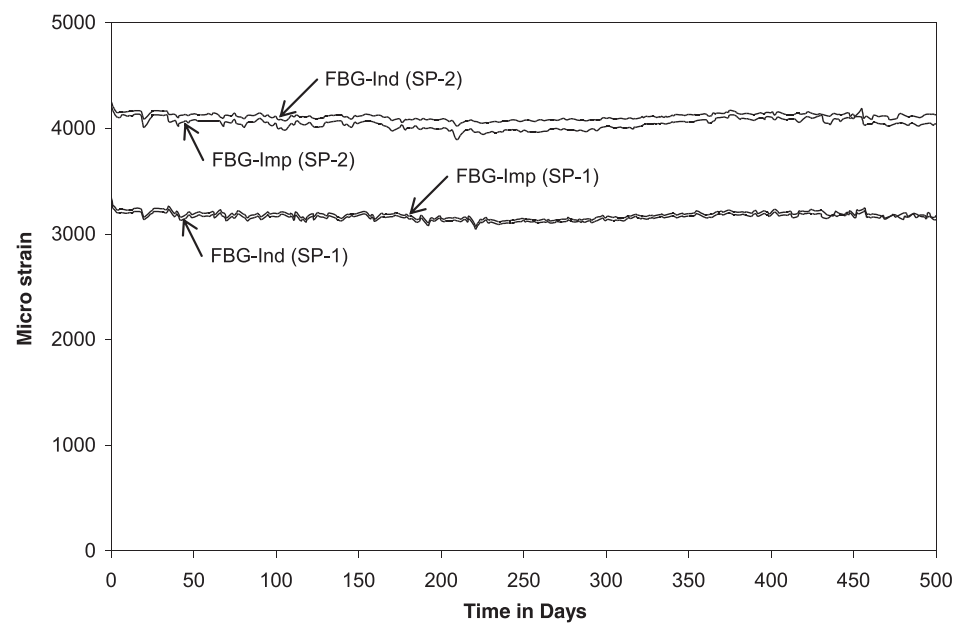

Figure 13. Plot of strain vs time long-term monitoring of pre-stressing wire. 


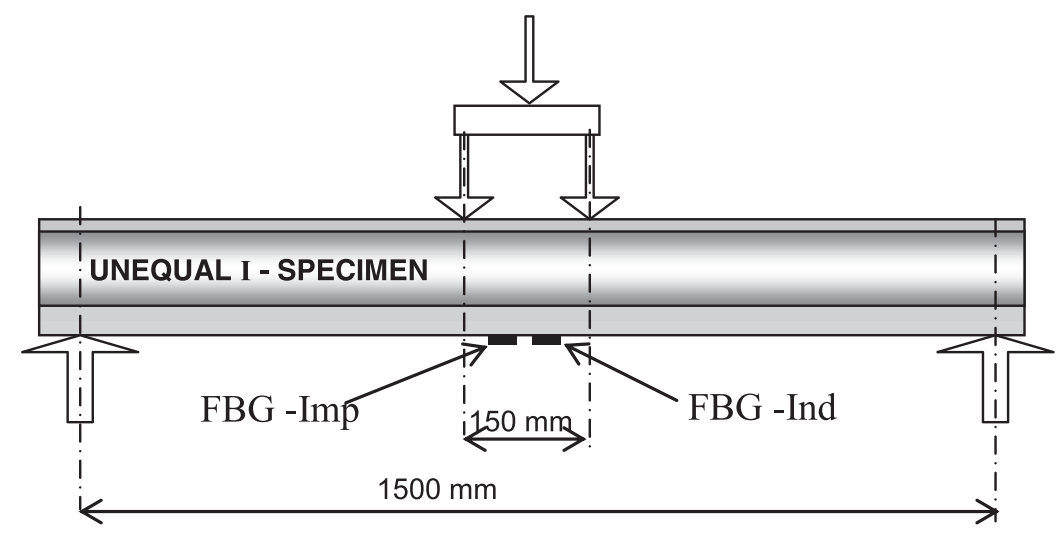

Figure 14. Instrumentation details of steel specimen for cyclic load test.

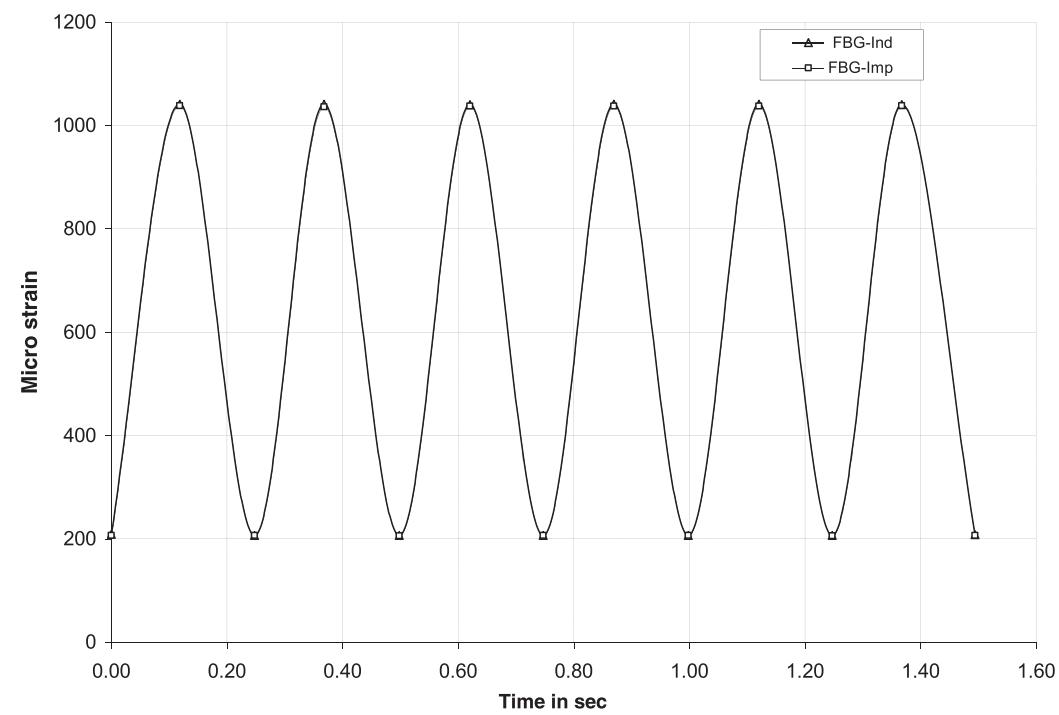

Figure 15. Typical response from FBG sensors during cyclic test.

\section{Summary}

Experimental studies were carried out to evaluate the performance of indigenously developed FBG sensors under monotonic and sustained loads and evaluated their suitability for short-term and long-term loading conditions. Performance assessment of the fibre optic sensor mounted on steel specimen under axial tension, concrete cylinder under axial compression was carried out. Relative performance of FBG sensor with conventional strain gages was carried out and the strain responses between the two types of sensors were found to be matching well. Studies were carried out to evaluate the performance of indigenous FBG senor for the measurement of thermal strain and temperature on a steel specimen. The temperature values obtained using the indigenous FBG sensors are also compared with temperature measured from strain gage based temperature sensor. 
Reliable measurement of strains over long period is an essential requirement for health monitoring of structures. Experimental studies were carried out to assess the long-term behaviour of indigenously developed FBG sensor on a pre-stressed wire subjected to sustained loading for a period of 500 days. From this investigation, it is concluded that strain output from the sensor is stable and hence FBG sensors are suitable for long-term/sustainable loading conditions. Performance evaluation of indigenously developed FBG sensors under cyclic load test was carried out up to 2 million cycles and the stability of the response was compared with imported FBG sensor. With the development of FBG sensor technology, monitoring of major civil engineering structures can offer an economic way of assessing the health and integrity of the structures.

\section{Acknowledgements}

Authors thank the Council of Scientific and Industrial Research (CSIR), India, for funding the research programme during 11th Five Year Plan through network project (NWP-026). This paper is being published with the permission of Director, CSIR-Structural Engineering Research Centre, Chennai.

\section{References}

Culshaw B and Dakin J 1996 Optical fibre Sensors, Volume 3, Components and subsystems, Artech House, Norwood, MA

Hill K O, Fujii Y, Johnson D C and Kawasaki B S 1978 Photosensitivity in Optical Fibre Waveguides: Application to Reflection Filter Fabrication. Appl. Phys. Lett. 32: 647-649

Kathy K 2006 Optoelectronic Applications: Fibre optic Sensing - Fibre sensors lay groundwork for structural health monitoring. Laser Focus World 42(2): 63-67

Kersey A D, Davis A M, Patrick H J, Michel Le Blanc, Koo K P, Askins C G et al 1997 Fibre grating sensors. J. Lightwave Technol. 15: 1442-63

Majumder M, Gangopadhyay T K, Chakraborty A K, Dasgupta K and Bhattacharya D K 2008 Fibre Bragg Gratings in Structural Health Monitoring-Present Status and Applications. Sensors and Actuators A: Physical 147(1): 150-164

Rao Y J 1999 Recent progress in applications of in-fibre Bragg grating sensors. Optics and Lasers Eng. 31: 297-324

Schulz W L, Udd E, Seim J M and McGill G E 1998 Advanced Fibre Grating Strain Sensor Systems for Bridges. Structures and Highways 3325: 212-221

Singh N, Jain S C, Mishra V, Poddar G C, Jindal V K, Bajpai R P and Kapur P 2007 Multiplexing of Fibre Bragg Grating Sensors for Strain and Temperature measurements. Experimental Technique 31(3): 54-56

Tenntson R C, Mufti A A, Rizkalla S, Tradors G and Benmokrane B 2001 Structural Health Monitoring of Innovative Bridges in Canada with Fibre Optic Sensors. Smart Materials and Structures 10: 560-573

Udd E 1995 Fibre Optic Smart Structures. New York: John Wiley \& Sons. Inc. 